\title{
Osteoblast Behavior on Silicon and Porous-Silicon Substrates
}

\author{
Asma Parveen ${ }^{1}$, Avinash Potluri ${ }^{2}$, Debasish Kuila ${ }^{2,3}$ and David K. Mills ${ }^{1,4, *}$ \\ ${ }^{1}$ Center for Biomedical Engineering and Rehabilitation Science, Louisiana Tech University, Ruston, LA 71272, USA \\ ${ }^{2}$ Institute for Micromanufacturing and Chemistry Program, Louisiana Tech University, Ruston, LA 71272, USA \\ ${ }^{3}$ Deptartments of Chemistry and Nanoengineering, North Carolina A\&T State University, Greensboro, NC 27411, USA \\ ${ }^{4}$ School of Biological Sciences, Louisiana Tech University, Ruston, LA 71272, USA
}

\begin{abstract}
Osteoblast viability, proliferation, protein expression and mineralization were studied on bare, micro- and nanoporous silicon (Si) substrates. Micro- and nano-porous-Si substrates were prepared by anodic etching of silicon in ethanolic hydrofluoric acid and characterized using scanning electron and atomic force microscopies. Mouse osteoblasts were cultured on these substrates and cellular response to these surfaces was assessed using the Live/Dead Cell Viability assay and the MTT assay for cell proliferation. Osteoblast functionality was assessed using immunohistochemistry for bone protein specific markers. Osteoblasts grew well on micro- and nanoporous silicon substrates over the twenty-one day experimental period supporting the assessment that these are suitable cell supportive surfaces. Cell proliferation rates on bare and nanoporous silicon were similar initially, however, nanoporous silicon displayed enhanced cell proliferation, in comparison to bare silicon, after 14 days in culture. Immunocytochemical assays, using bone specific markers, showed positive reactions for osteonectin and osteopontin expression on all substrates with staining intensity increasing over the 21-day experimental period. Calcium mineral deposits were quantified using the Alizarin Red histochemical assay and nanoporous silicon induced the highest level of calcium mineral production in comparison to bare and microporous silicon. The data supports the potential use of nanoporous silicon as a surface implant coating for dental and orthopedic applications. The ability to dope (and then release) drugs or growth factors from the silicon nanopores offers the potential for a multifunctional implant surface.
\end{abstract}

Received on 14-12-2016 Accepted on 06-01-2017 Published on 14-06-2017

Keywords: Porous-Si, anodic etching, implant surfaces, osteoblasts.

\section{INTRODUCTION}

Dental and orthopedic appliances, devices, and implants (hereafter grouped as 'implants') have been in widespread use for over fifty years. Advances in surgical techniques and population longevity have drastically increased both the need and demand for dental and orthopedic procedures worldwide [1]. Dental and orthopedic complaints (dysfunction, impairment, pain) are the major reason that most Americans seek clinical intervention. In the United States alone, more than half a million people undergo total joint replacement each year and over 50 million yearly receive some form of dental or orthopedic device or implant [2]. Worldwide, total joint replacements have been estimated at 959,000 annually, including both primary and revision total hip procedures [1, 2].

Infection of dental and orthopedic implants due to postsurgical infection by bacteria or fungi remains a serious issue

"Center for Biomedical Engineering and Rehabilitation Science, Louisiana Tech University, Ruston, LA 71272, USA; Tel: (318) 257-2640; Fax: (318) 257-4574;

E-mail: dkmills@latech.edu despite the common pre-surgical practice of disinfection [3-5]. Bacterial adsorption and surface colonization of the implant surface $[4,5]$ and failure of the implant to integrate with surrounding tissues [5-7] are the leading causes of implant failures as well as the resulting sequela that affects a patient's recovery. Resolving an implant infection usually requires that the implant be removed entirely, surrounding tissue cleaned of infection, and then a second prosthetic device is implanted. Revision arthroplasties and increased hospital stays can cost hundreds of thousands of dollars for a single patient. There are additional drawbacks to replacement surgeries including: inferior recovery compared to the initial surgery, further postsurgical complications and pain, reduced host defense, significant lost time from work, altered and restricted lifestyles, and even death. Current statistics indicate that infection is responsible for causing implant failure in approximately $1 \%$ of hip implants, $4 \%$ of knee implants, and more than $15 \%$ of implants associated with orthopedic trauma, where the wounds are deep, often dirty from debris such as seen in accident or battlefield injuries [810]. 
The second most common cause for implant failure is poor tissue formation on the implant surface leading to poor or incomplete osseointegration with surrounding tissues that can result in implant loosening and instability [11, 12]. Osseointegration is defined as a direct structural and functional linkage between the surrounding living bone and the implant surface, and is crucial for implant stability, and is also considered a prerequisite for resistance to applied loads and the long-term clinical success of the implant (and for patient compliance) [13, 14].

Natural bone is nanoporous at the surface and an ideal medium for cell attachment and functionality. Smooth titanium, commonly used, does not directly support cell attachment, growth and functionality [15]. Depending on the manufacturing process, the surface of titanium can be easily modified; surfaces can be highly polished, anodized, or texturized and it can be shaped into different forms that target specific types of surgical appliances, devices or implants. A major consideration in designing implants for integrations has been to produce surfaces that determine cell-surface interactions after implantation and promote desirable responses in adjacent cells namely, cell attachment, proliferation, and phenotypic expression, in particular the production of bone specific proteins such as osteocalcin or osteopontin. The most important surface features that influence the rate and degree of osseointegration include: surface chemistry, topography, wettability, charge, surface energy, topography and crystallinity, roughness, chemical potential, strain hardening, and the presence of impurities $[13,14]$. Numerous methods have been used to create a nanoporous surface and achieve the desired surface features including blasted surfaces, chemical etching, anodization, porous-sintering, oxidizing, plasma-spraying and hydroxyapatite-coated surfaces, as well as combinations of these procedures (extensively reviewed in references [13-15]).

While the efforts to produce biocompatible surfaces to date have been encouraging, no technique has been totally successful in preventing post-surgical infections and enhancing implant integration. It is clear that the dental and orthopedic community need new multi-functional surface coatings with long-term antibacterial properties that prevent biofilm formation on implant surfaces and also encourage neotissue formation that promotes successful integration into surrounding tissues. Porous silicon has received much recent attention in the field of bone tissue engineering because of its mechanical strength, ability to be easily manipulated into any desired shape, optimal degradation kinetics, and excellent surface properties that mimic the natural in vivo environment $[16,17]$. Of the surface modification methods employed, anodization holds the most promise in designing an implant surface that is nanoporous thus creating a large surface area that can be functionalized as an application warrants including doping with various drugs or osteogenic agents. This study assessed osteoblast behavior on bare, micro- and nanoporous silicon scaffolds prepared by anodic oxidation.

\section{MATERIALS AND METHODS}

\subsection{Materials}

P-type, boron-doped silicon (Si) wafers with <100> orientation, resistivity of 6-9 $\Omega-\mathrm{cm}$ and polished front sides were purchased from Montco Silicon Technologies Inc., CA. Acetone, ethanol, hydrofluoric acid (HF) and MTT cell culture test kit were purchased from Sigma-Aldrich, USA. Minimum Essential Medium, Alpha (AMEM) and Fetal Bovine Serum, Premium (FBS) were purchased from Mediatech, Inc. makers of Cellgro, Herndon, VA. Live-Dead Cell staining kit was purchased from Biovision, Mountain View, CA. Primary antibodies MPIIIB10 and AON-1 were purchased from Developmental Studies Hybridoma Bank, The University of lowa. Secondary antibody fluorescein-conjugated goat IgG fraction to mouse IgG was purchased from Cappel, MP Biomedicals, Santa Ana, CA.

\subsection{Fabrication of Porous Silicon}

Micro- and nanoporous silicon were formed by the electrochemical dissolution of silicon in an HF-based electrolyte. An anodization cell, a single-cell approach using a backside contact, was used for porous silicon fabrication. Al foil provides the back contact to silicon wafer on which PS was formed. The silicon wafer indirectly acts as anode as it is in close contact with Al foil, which is directly connected to the anode. The electrolytic mixture of hydrofluoric acid and ethanol was poured over the silicon wafer in the opening present on the top etch cell. A platinum wire was used as a cathode [18].

The fabrication of PS depends on three parameters: current density, concentration of electrolyte, and time of etching. Experiments were carried out using current density in the range of 10 to $100 \mathrm{~mA} / \mathrm{cm}^{2}$ typically for $10-15$ mins to examine the effect of current on pore size of porous- Si. For the fabrication of microporous silicon, a 1:1 mixture of $\mathrm{HF}$ and ethanol was used as an electrolyte, and a typical current density of $50 \mathrm{~mA} / \mathrm{cm}^{2}$ was applied for $8-10$ minutes. For nanoporous silicon fabrication, a typical current density of 25 $\mathrm{mA} / \mathrm{cm}^{2}$ was applied for 3-5 minutes, with the same concentration of electrolyte. Ethanol was used as a pilot study and showed that its application resulted in a more structurally uniform porous layer, increased the wettability of the silicon, and reduced the formation of hydrogen gas bubbles.

\subsection{Scanning Electron Microscopy}

AMRAY 1830 Scanning electron microscopy (SEM) was used primarily to observe the surface topography of the silicon substrates after etching at different current densities. Electrically conductive carbon tapes were used for mounting the samples on the SEM pin mount specimen holder. Doublesided adhesive tape was used as it allows for faster sample mounting with no liquid or colloidal adhesives. For higher 
resolution images, a Field-emission SEM at Louisiana Tech was used to characterize the topography of the surfaces.

\subsection{Atomic Force Microscopy}

Atomic Force Microscopy (AFM, Quesant, Model 250) was used to characterize the substrate surface. The AFM was used in tapping mode with silicon cantilever to measure the surface roughness of the substrates in dry state. The parameters used for the measurements were a scan area of $40 \times 40 \mu^{2}$, scanning rate between $1.5-2 \mathrm{~Hz}$, and a resolution of 600 lines.

\subsection{Cleaning of Porous Silicon Substrates}

Porous silicon substrates were cleaned by sonication in acetone, ethanol, for 10 mins each and then in DI water for 10 minutes. The substrates were then rinsed, $\mathrm{N}_{2}$-dried and used for experimental assays.

\subsection{Osteoblast Cell Culture}

Substrates were immersed in $70 \%$ ethanol overnight for sterilization. The substrates were removed from ethanol and washed twice with Hank's balanced salt solution (HBSS) and once with complete media. Cells were cultured in aMEM supplemented with $300 \mathrm{mg}$ of L-glutamine powder, $1 \%$ penicillin-streptomycin and 10\% FBS, and incubated in a humid, $5 \% \mathrm{CO}_{2}$ atmosphere at $37^{\circ} \mathrm{C}$. Cells were seeded onto the porous silicon substrates at the desired densities, considering the volume of the whole dish, not just the substrate. Planar silicon substrates seeded with cells were used as control. The dishes containing the cell-seeded substrates were then incubated at $37^{\circ} \mathrm{C}$ in $95 \%$ humidified air and $5 \% \mathrm{CO}_{2}$. Osteoblasts were seeded at a density of 12,000 cells $/ \mathrm{cm}^{2}$ for Live-Dead assay and Evans Blue staining. Osteoblasts were seeded at a density of $8,000 \mathrm{cells} / \mathrm{cm}^{2}$ for MTT and Alizarin Red assays.

\subsection{Cell Visualization and Viability Assays}

The dark background of porous silicon prevents standard viewing of cells in culture under phase contrast microscopy. Images taken were restricted to the outer edge of the scaffolds because of their opaqueness and were captured using an Olympus BX51 fluorescence microscope. We used an Evans Blue staining to aid in visualization. Evans Blue is a diazo dye that due to its brilliant blue color and ability to remain inside cells was used to visualize osteoblast attachment and subsequent behavior on the substrates. Evans blue stains the cells blue but leaves the remaining area unstained, thus easily differentiating the cells from the substrate surface.

The viability studies were performed using a Live/Dead Cell staining kit obtained from Biovision. The kit contains Live$\mathrm{Dye}^{\mathrm{TM}}$ a cell-permeable green fluorescent dye $(\mathrm{Ex} / \mathrm{Em}=$ $488 / 518 \mathrm{~nm}$ ), to stain live cells in green, and propidium iodide $(\mathrm{PI})$, a cell non-permeable red fluorescent dye $(\mathrm{Ex} / \mathrm{Em}=$
488/615), to stain dead cells in yellow-red. For viability studies staining solution was prepared by mixing $1 \mu \mathrm{l}$ of Solution A ( $1 \mathrm{mM}$ Live-Dye) and $1 \mu \mathrm{l}$ of Solution B $(2.5 \mathrm{mg} / \mathrm{ml}$ $\mathrm{PI})$ to $1 \mathrm{ml}$ of Staining Buffer. The seeded substrates were washed twice with HBSS and then $150 \mu \mathrm{l}$ of staining solution was added to each substrate. These substrates were then incubated at $37^{\circ} \mathrm{C}$ for 15 minutes. Slides were assessed for cell viability and observed on day 7 , day 14, and day 21 using an Olympus BX51 epi-fluorescence microscope and representative images were captured using a Nikon digital camera connected to it.

\subsection{Cell Proliferation Assay}

Cell proliferation was determined using thiazolyl blue tetrazolium bromide powder-MTT assay kit. This assay works on the principle of measuring the activity of living cells via mitochondrial dehydrogenase activity. Mitochondrial dehydrogenase of live cells cleaves to tetrazolium ring producing purple MTT formazan crystals which can be dissolved using isopropyl alcohol and their absorbance measured using a TECAN plate reader. For MTT assay MTT solution was prepared by dissolving $5 \mathrm{mg}$ of thiazolyl blue tetrazolium bromide powder in $1 \mathrm{ml}$ of HBSS. MTT solvent was prepared by adding $310 \mu \mathrm{l}$ of $0.04-0.1 \mathrm{~N} \mathrm{HCl}$ to $100 \mathrm{ml}$ of $99.9 \%$ anhydrous Isopropanol. Media in culture dishes was drained and the seeded substrates were transferred to fresh dishes. A solution containing $10 \%$ of the media as MTT

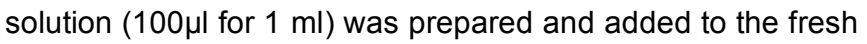
dishes containing transferred substrates. This solution was also added to an empty dish without cells and taken as blank. The cells along with the blank were incubated at $37^{\circ} \mathrm{C}$ for 4 hrs. After $4 \mathrm{hrs}, 1 \mathrm{ml}$ of MTT solvent was added to each well including the blank to dissolve the purple formazan crystals formed, because of the interaction of the MTT solution with the cells. The absorbance of the resultant solution and the blank was read using a spectrophotometer at $570 \mathrm{~nm}$ with background subtraction at $690 \mathrm{~nm}$. The difference in the absorbance of the resultant solution and the absorbance of the blank gave the absorbance of purple crystals alone, which was then correlated with a calibration curve to obtain their corresponding cell densities.

\subsection{Immunofluorescence Assay}

Immunofluorescence assay were conducted on osteoblasts to observe for expressions of bone proteins such as osteopontin and osteonectin. For immunofluorescence assay seeded substrates were incubated at $37^{\circ} \mathrm{C}$ with $3.7 \%$ paraformaldehyde solution for 30 minutes-60 minutes at $4 \mathrm{C}$. The substrates were then permeabilized with $1 \%$ Triton $X$ 100 in PBS for 10 minutes at room temperature and rinsed well with PBS. The cells were then blocked with non-immune blocking serum or $1 \%$ BSA in TBST or PBST for 30 mins at room temperature. Non-immune blocking serum was pipetted and the excess was wiped off carefully. Undiluted supernatant primary antibodies were applied and the 
substrates were incubated for 60 mins at $37^{\circ} \mathrm{C}$. The substrates were then washed quickly once with PBS and allowed to be in fresh PBS solution for 10 minutes Secondary antibody was then applied and incubated at room temperature for $45-60$ minutes. Typical dilution of 1:250 was used and the secondary antibody was applied in dark. The cells were quickly washed with PBS and then allowed to be in fresh PBS for 10 mins in the dark. Finally, slides were prepared using fluorescent mounting media. Images were captured at an interval of day 7 , day 14, and day 21 using a digital camera connected to the fluorescence microscope.

\subsection{Alizarin Red Assay}

Alizarin Red assay was performed to quantify the calcium mineral deposits of osteoblasts. For Alizarin Red assay, 40 $\mathrm{mM}$ of Alizarin Red solution was prepared by dissolving 137 mg of AR-S powder in $10 \mathrm{ml}$ of Type-I water. The seeded substrates were fixed with $75 \%$ ethanol and placed in fridge for 30-60 minutes. These substrates were then stained with the Alizarin Red solution for 10-15 mins, which produces an orange-red color due to the formation of Alizarin Red Scalcium complex by a chelation process. Type-I water was then added and mixed thoroughly to dissolve the stain and the absorbance of the resultant solution was measured using an UV-Spectrophotometer. Using an optical density and the calibration curve, the calcium mineral levels were determined.

\subsection{Statistical Analysis}

The Student's T-test was applied for statistical analysis, with means and standard deviations (SD) calculated for statistical documentation. Quantitative analyses of fibrochondrocyte proliferation and functionality were analyzed using two-way ANOVA. Results of the protein assays and the proliferation assays represent a mean of three trials $(p<0.05)$

\section{RESULTS}

\subsection{Scanning Electron Microscopy}

Micro- and nano-porous-Si substrates were prepared under different anodization conditions. The surface morphology of the porous silicon such as thickness of porous layer, pore diameter etc. was studied using scanning electron microscopy (SEM). As shown in Figure 1, the uniform pores are formed throughout the surface. This homogenous formation of pores is due to the addition of ethanol (surfactant) in the electrolytic mixture. Figure 1 (lower panel, $D$ to $F$ ) shows the cross-sectional view of porous silicon from which the thickness of the porous layer formed can be measured. From the cross-sectional view we can clearly distinguish between the regular silicon and the porous silicon. A porous silicon layer of thickness $4-5 \mu \mathrm{m}$ was formed on the surface. Cross-sectional scanning electron micrographs of
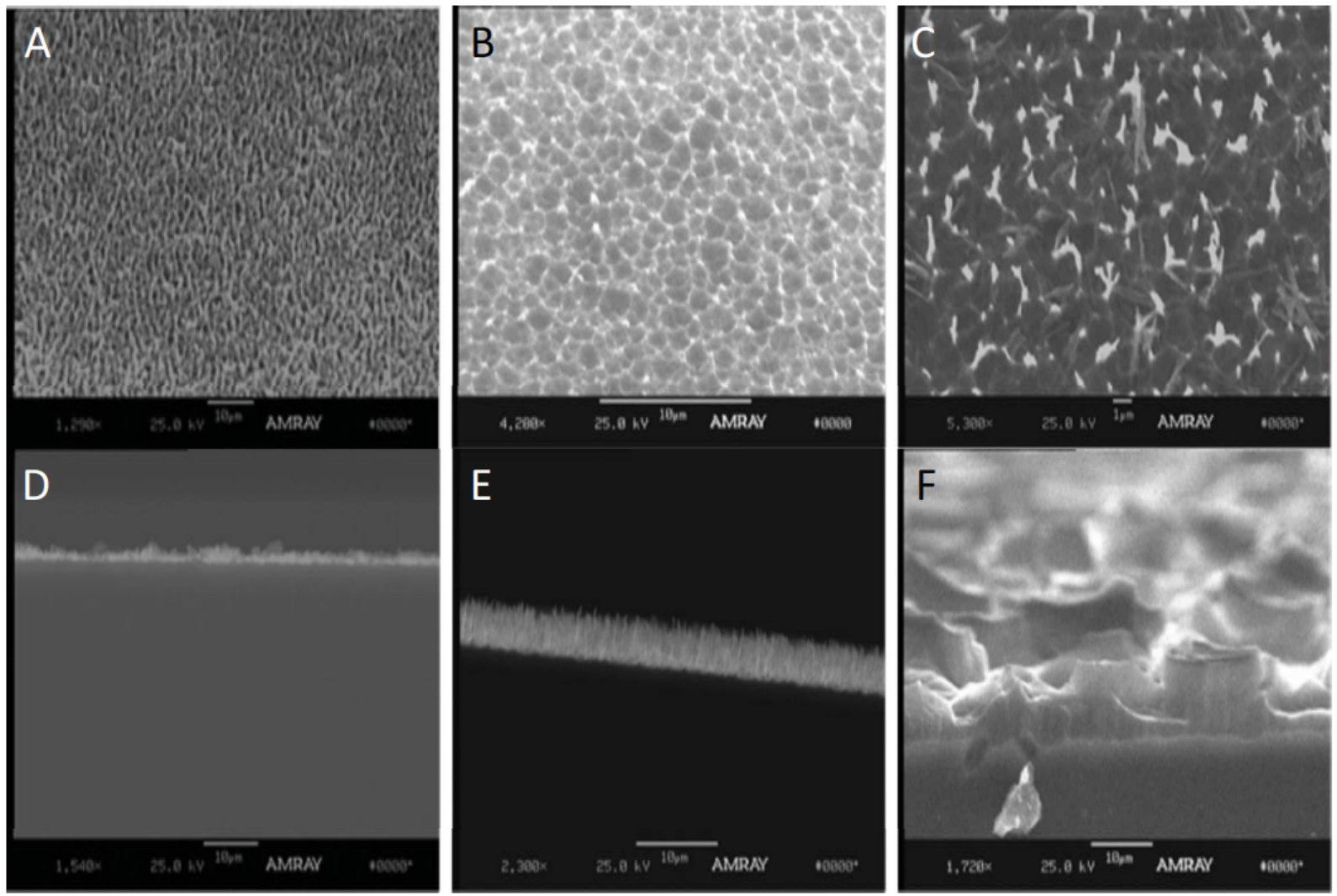

Figure 1: SEM Microscopy. Upper tier displayed SEM micrographs of porous silicon prepared at different anodization conditions. (A) $10 \mathrm{~mA} / \mathrm{cm}^{2}$ for $15 \mathrm{~min}$, (B) $50 \mathrm{~mA} / \mathrm{cm}^{2}$ for $15 \mathrm{~min}$, C)) $100 \mathrm{~mA} / \mathrm{cm}^{2}$ for $15 \mathrm{~min}$. Lower tier micrographs show cross-sectional views of porous silicon samples etched at different current densities: (C) $10 \mathrm{~mA} / \mathrm{cm}^{2}$ for $15 \mathrm{~min}$, (D) $50 \mathrm{~mA} / \mathrm{cm}^{2}$ for $15 \mathrm{~min}$, E) $100 \mathrm{~mA} / \mathrm{cm}^{2}$ for $15 \mathrm{~min}$. 
porous silicon show that pore formation occurs in a unidirectional fashion from the surface into the bulk, leaving aligned pores and columnar silicon structures.

Figure 1 (upper panel, $A$ to $C$ ) shows the top view of porous silicon formed at different current densities. The anodization time was kept at 15 mins in all the cases. The pore diameter increased with the increase in the current density. The porous-Si is classified as micro- or nano-porous depending on the pore diameter. The average pore size is less than $<1$ um at current density of $10 \mathrm{~mA} / \mathrm{cm}^{2}$ (A, the top left). Although we could not calculate the surface area accurately, an increase of $121 \%$ in surface area was observed in microporous-Si when compared to that of regular Si. For nanoporous-Si an increase of over $350 \%$ was observed. The cross-sectional view, shown in bottom 3 Figures, was obtained at current densities of $10 \mathrm{~mA} / \mathrm{Cm}^{2}, 50 \mathrm{~mA} / \mathrm{Cm}^{2}$ and $100 \mathrm{~mA} / \mathrm{cm}^{2}$, respectively. The thickness increased from $\sim 1$ um to $\sim 4$ um to $\sim 7$ um. The porosity of the material increased from 50 to $80 \%$ with increase in time of etching.

\subsection{Atomic Force Microscopy}

Atomic Force Microscopy (AFM) studies of porous silicon mainly focused on the nanoscale characterization of the layers. AFM characterization provides important information on surface roughness, size of pores etc. Due to the geometry of the tips commonly used, AFM does not allow the imaging of deep pores. Also AFM allows only the imaging of the top end of the pores, which is a disadvantage compared to that obtained from electron microscopy. The AFM images of micro- and nano-porous silicon are shown in Figure 2.
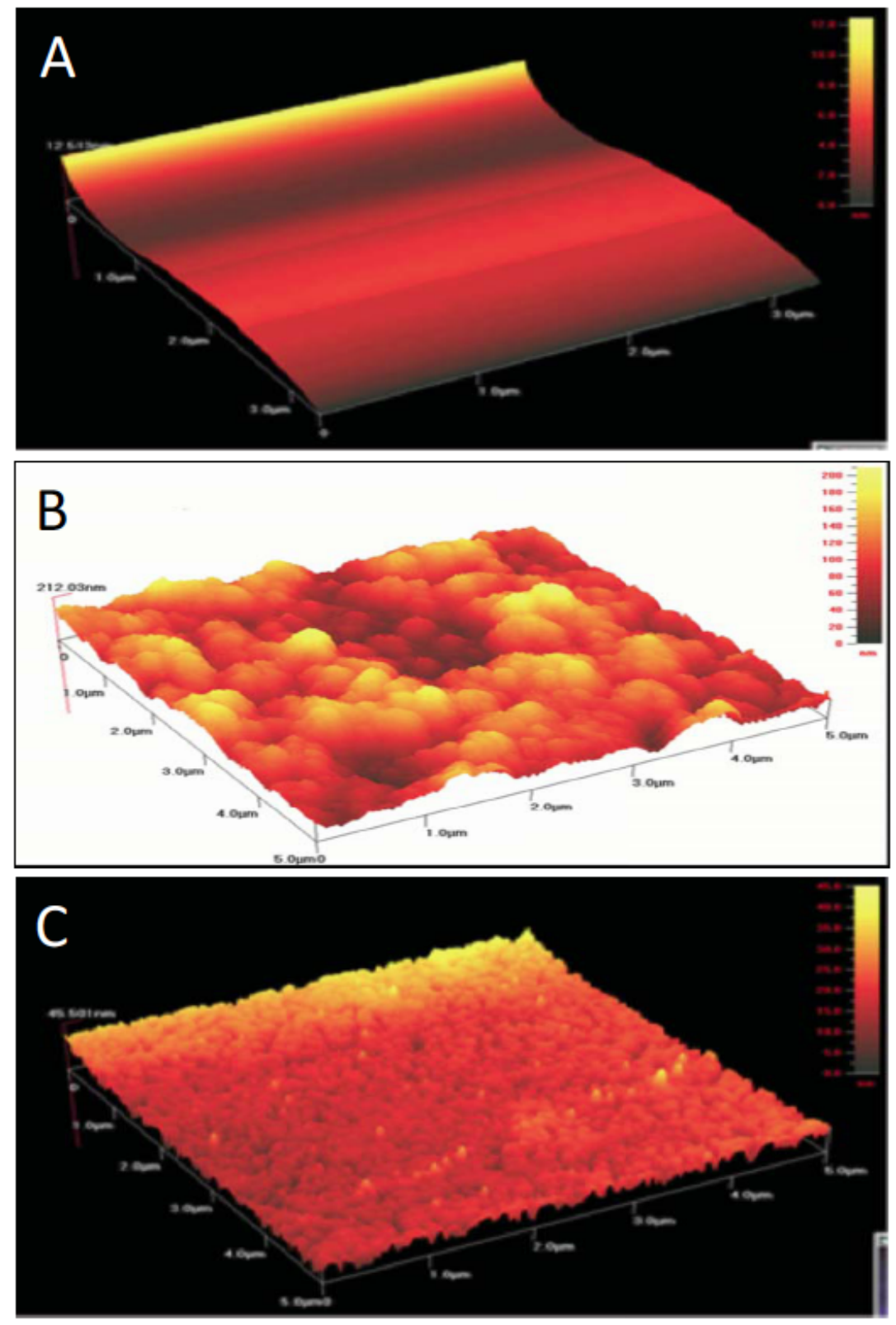

Figure 2: AFM images of: (A) Bare silicon (B) Microporous silicon. (C) anoporous silicon. 
Depending on the pore diameter, porous silicon can be simply classified as micro-porous silicon and nano-porous silicon. Nano-porous silicon was formed by electrochemical etching of silicon wafer at a current density of $10 \mathrm{~mA} / \mathrm{cm}^{2}$ for 2-3 mins. The surface roughness of nano-porous silicon is less compared to that of micro-porous silicon. Difference in the pore penetration (pore depth) between the micro-porous silicon and nano-porous silicon can be observed from the AFM pictures. The maximum difference between the crest and a trough in nano-porous silicon is $45 \mathrm{~nm}$ and $212 \mathrm{~nm}$ in micro-porous silicon. It should be noted that, the pore depth obtained from the AFM analysis cannot be considered as the total pore depth of porous silicon because, AFM can image only the top portion of the pores.

The height histogram analysis (data not shown) gives the average height of the pores present on the top layer of porous silicon. For the micro-porous silicon, the average height is observed to be $246 \mathrm{~nm}$ and for nano-porous silicon it is $4 \mathrm{~nm}$. Pore sizes of $11 \mathrm{~nm}$ and $2 \mu \mathrm{m}$ for nano- and microporous silicon can be estimated from Figure 1.

\subsection{Cell Density and Morphology on Silicon Substrates}

As revealed by Evans Blue staining osteoblasts attached to all silicon surfaces (Figure 3). Osteoblasts attached easily to all surfaces with apparent cell density greatest on nanoporous silicon after one day in culture. At seven days, apparent cell density was greatest on bare and nanoporous silicon (Figure $\mathbf{3} \mathbf{A}$ and $\mathbf{G}$ ). Cells density increased through day 21 (Figure 3). At day 21, the greatest apparent cell density was observed on microporous and nanoporous silicon surfaces $(F$ and $I)$. Cell growth on microporous surfaces lagged behind as compared with bare and nanoporous substrates until day 21. Osteoblast morphology changed from a spindle shaped morphology at 7 days to a more polygonal shape at day 21 and as osteoblasts approached near confluency on all substrate surfaces.

\subsection{Cell Viability}

Live Dead analysis revealed that cell grew on all substrates and the pattern of cell growth mirrored that obtained with Evan's Blue staining. Cell viability was slightly higher on nanoporous silicon (Figures $4 \mathrm{C}$ ) in comparison to bare silicon (Figure 4A) on day 7 with the lowest cell viability observed on microporous silicon (Figure 4B). Cell remained viable on all surfaces with an apparent increase in cell density by day 14 with very few dead cells observed on any of silicon substrates (data not shown). On day 21, cell viability remained highest on nanoporous silicon (Figure $4 \mathrm{~F}$ ) in comparison to bare silicon (Figure 4D) and microporous silicon (Figure 4E). Light
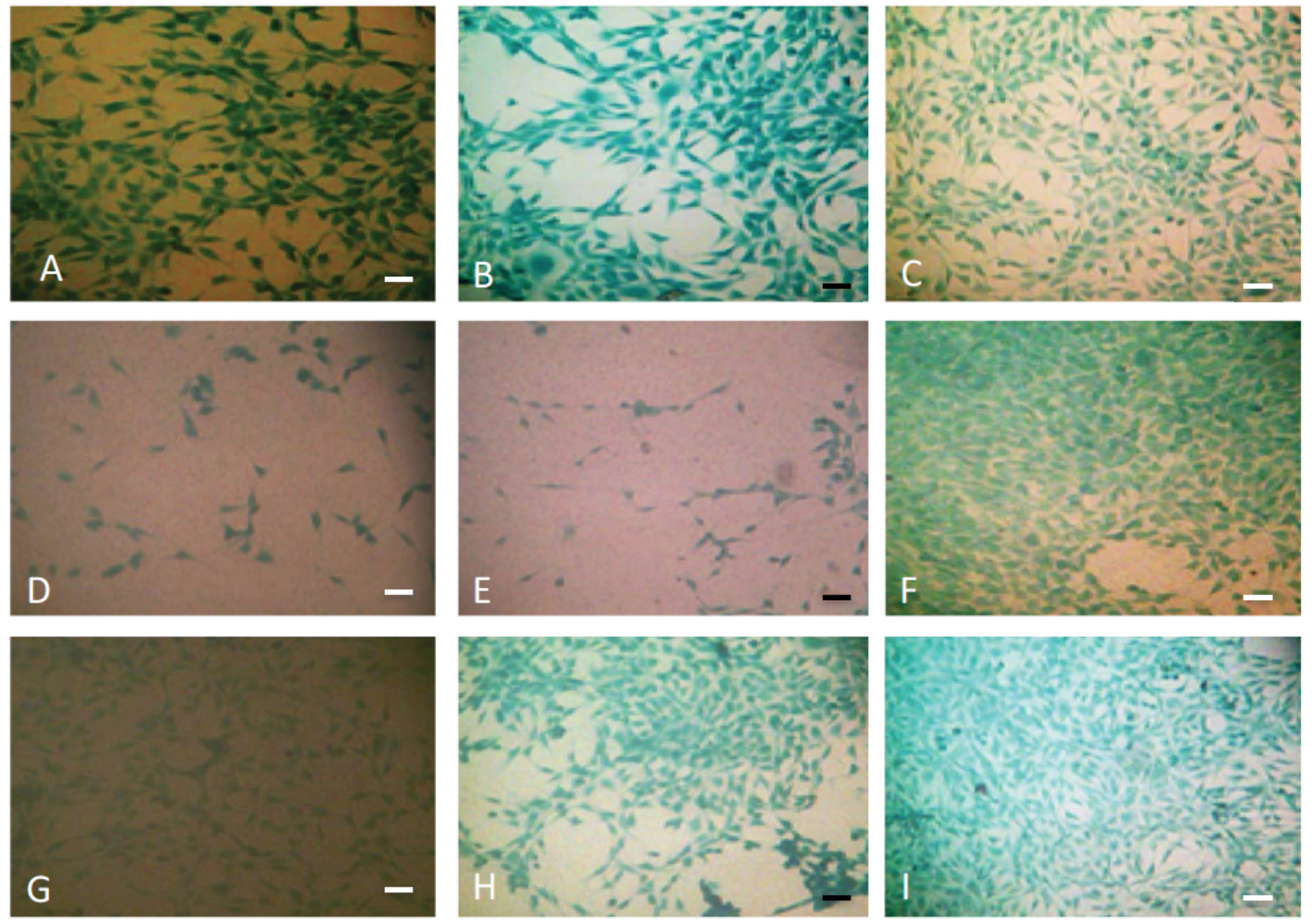

Figure 3: Evans Blue staining of osteoblasts over the 21-day experimental period on bare (A,B,C), microporous (D,E,F) and nanoporous silicon $(\mathbf{G}, \mathbf{H}, \mathbf{I})$. Cell density and viability on day 7 (A-C) shows osteoblasts thrived on bare (A) and nanoporous surfaces (C). Cells density increased through day 21 . At day 21, the greatest apparent cell density was observed on bare and nanoporous silicon surfaces $(\mathbf{F}$ and $\mathbf{I})$. Scale bar $=40$ microns. 

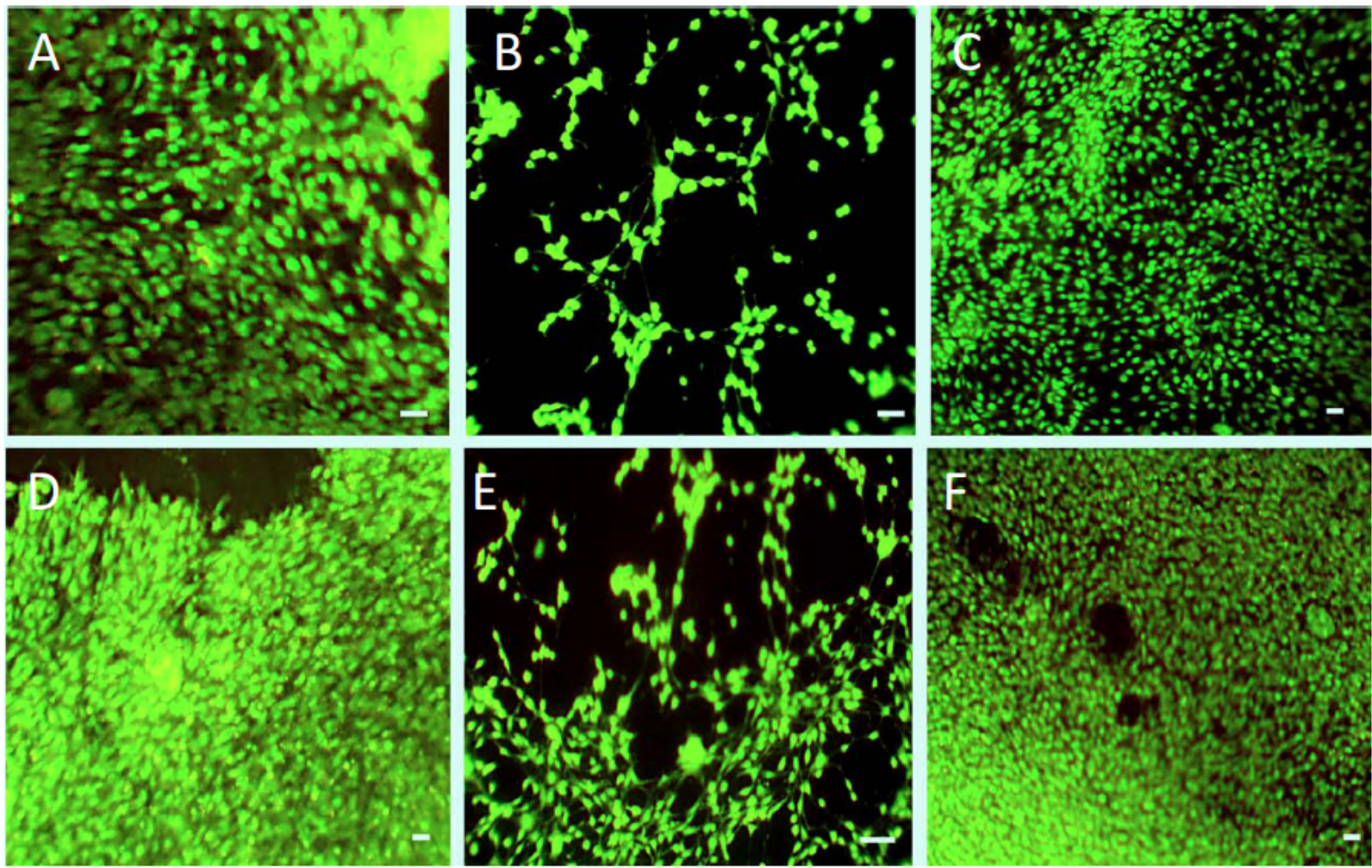

Figure 4: Cell viability of osteoblasts on bare $(\mathbf{A}, \mathbf{D})$, microporous $(\mathbf{B}, \mathbf{E})$ and nanoporous silicon $(\mathbf{C}, \mathbf{F})$. Green fluorescence indicates the presence of live cells. Cell density and viability on day 7 (A-C) shows osteoblasts thrived on bare (A) and nanoporous surfaces (C). Cells density increased through day 21 and cell viability again was greatest on bare and nanoporous silicon surfaces (D and F). Cell growth on microporous increased through day 21 but cell density was much less in comparison to bare and nanoporous substrates. Scalebar $=20$ microns.

microscopic observations showed that apparent cell density increased slightly from day 14 to day 21 in the case of microporous silicon (compare Figure 4B with Figure 4E). Red-labeled cells, indicating dead cells, did not appear to any great extent on any of the substrates and all the substrates can be considered to be cytocompatible.

\subsection{Cell Proliferation Results}

As shown in Figure 5, it was observed that cell density on both bare and nanoporous silicon increased gradually with time. Cell density was highest on nanoporous silicon in comparison to both bare and microporous silicon. Only in the

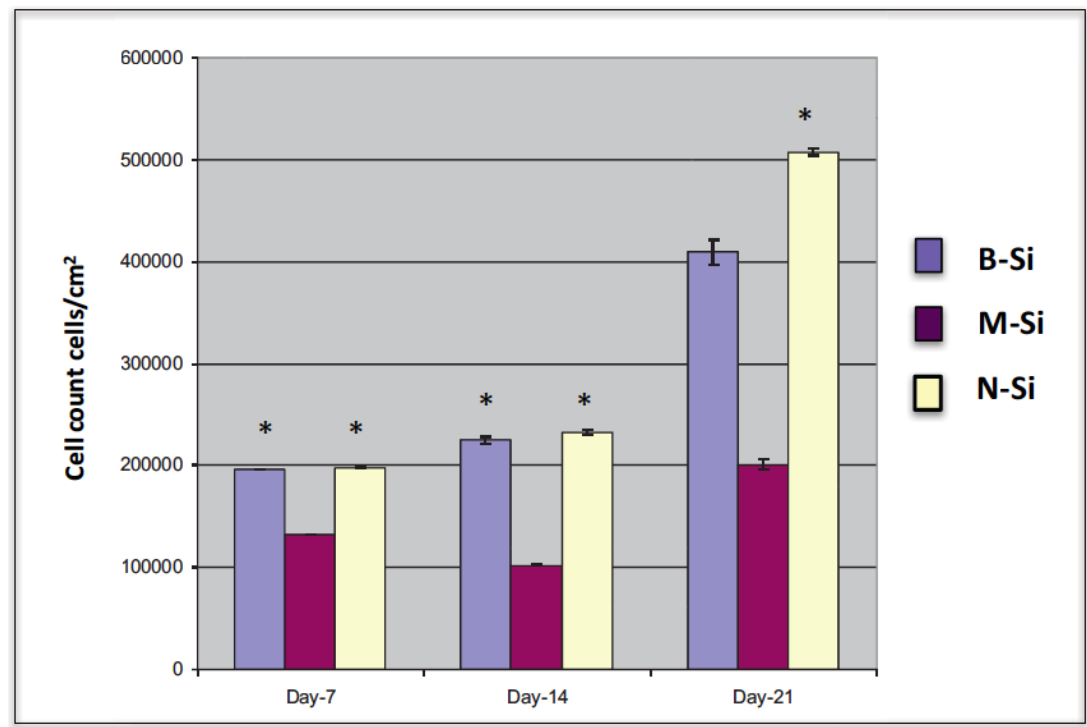

Figure 5: Plot of variation in number of cells $/ \mathrm{cm}^{2}$ vs. time after osteoblasts were cultured on bare (B-Si), microporousand (M-Si) and nanoporous silicon $(\mathrm{N}-\mathrm{Si})$. Results represent a mean of three proliferation trials $(\mathrm{p}<0.05)$. 
case of microporous silicon was there a decrease in cell density from day 7 to day 14 , and thereafter the cell density increased after 21 days.

Statistically, significant differences were observed for bare, micro and nanoporous silicon at $\alpha=0.1$. At $\alpha=0.05$, significant differences in cell proliferations were observed with bare and nanoporous silicon as compared with microporous silicon.

\subsection{Immunofluorescence Response of Osteoblasts for Osteopontin and Osteonectin}

Immunofluorescent analysis showed immunopositive reactions for osteopontin (Figure 6) and osteonectin (Figure 7) with prominent and specific fluorescence reactions expressed within the cells. Controls immunostained without primary antibody treatment (Figure $\mathbf{6 A}$ ) on bare, micro and
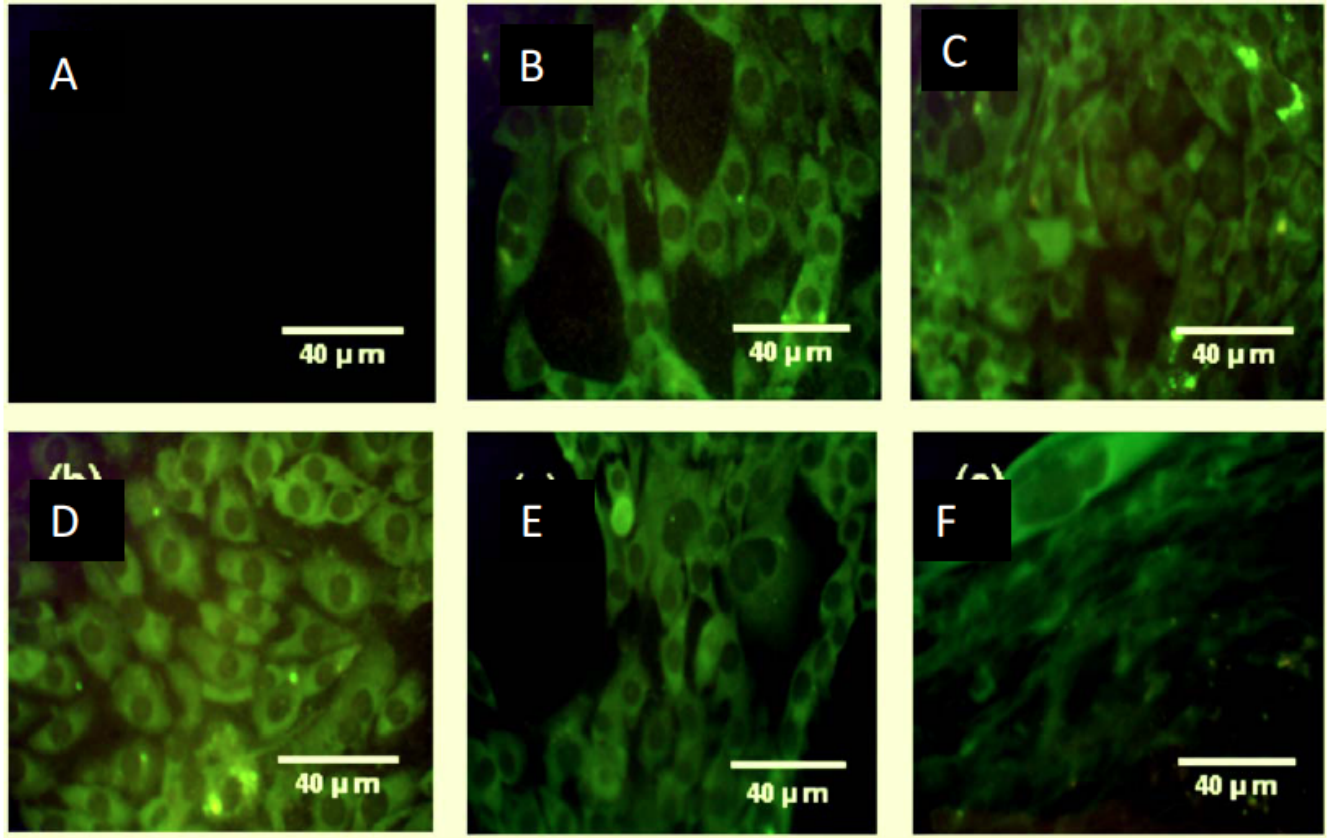

Figure 6: Immunohistochemistry of the bone specific protein, osteopontin, on silicon substrates. Controls showed negative staining for osteopontin on day 7. Controls revealed no staining on days 14 and 21. (A). Positive staining for osteopontin was observed in osteoblasts at day 7 on microporous silicon (B) and nanoporous silicon (C). Positive staining was also observed on micro and nanoporous surfaces on day 14 , $(D, E)$ and on nanoporous surfaces on day 21 although the staining intensity was reduced $(F)$.
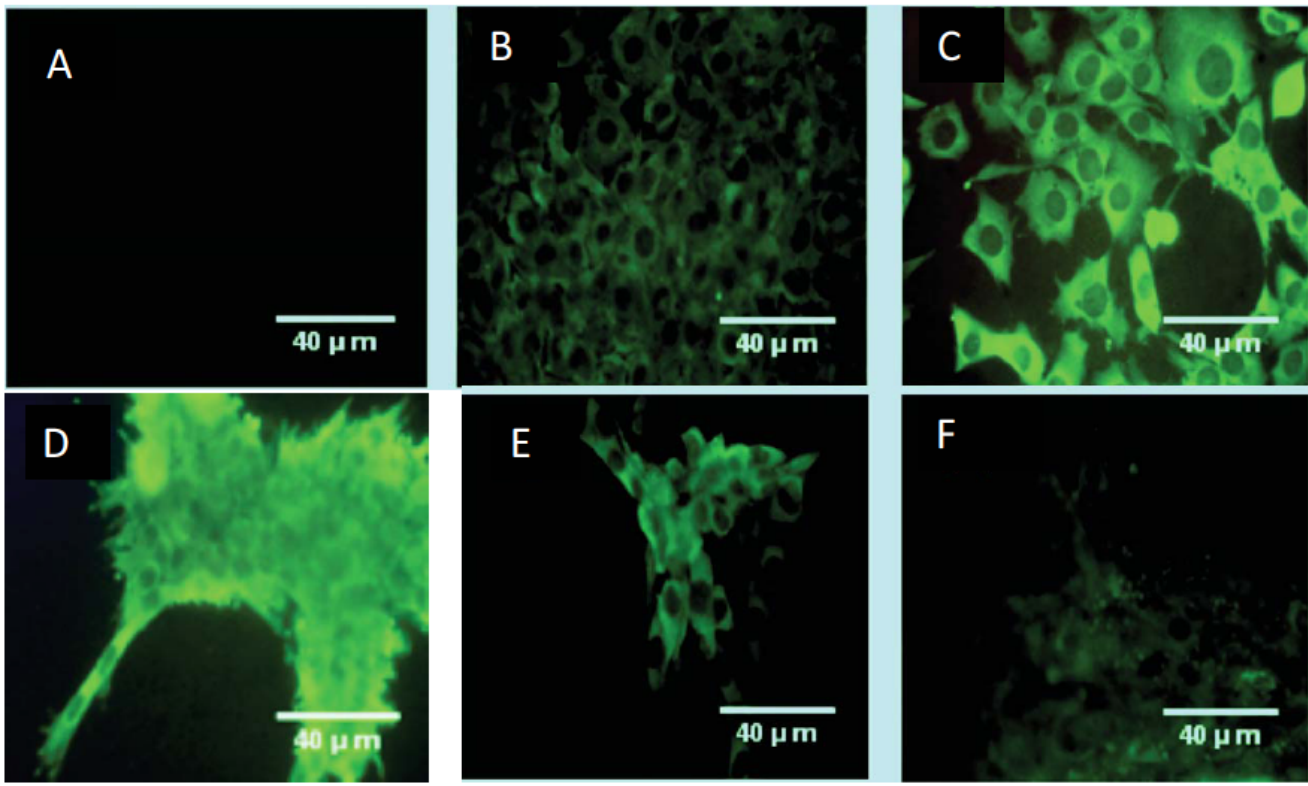

Figure 7: Immunostaining for osteonectin. Upper tier. (a) Control, day 7; Osteonectin showed positive staining on bare (A) and microporous surfaces, day 7 (c). Lower tier. Positive osteonectin increased inintensity from day through day 21 on bare silicon (a) microporous silicon (b) and nanoporous silicon, day 21 . 


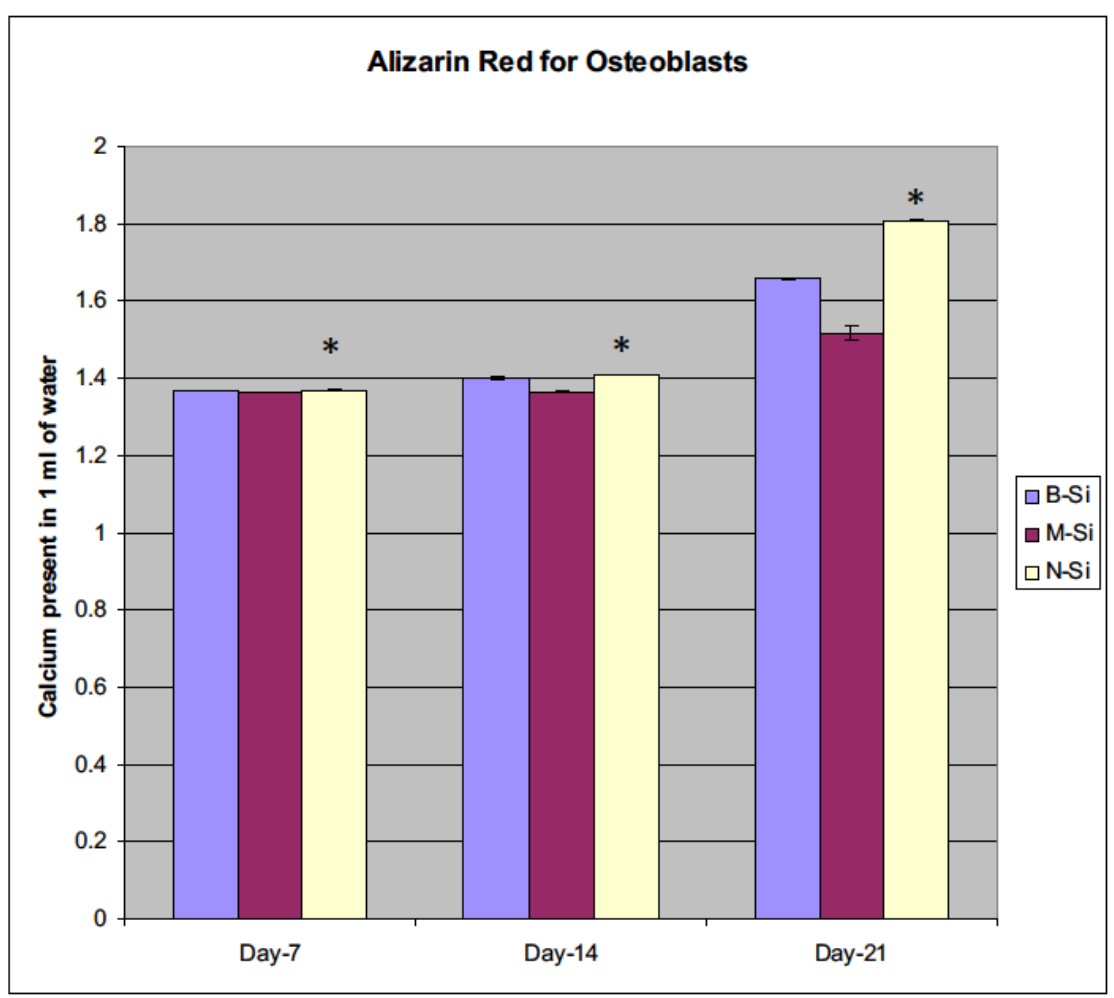

Figure 8: Plot of variation in calcium mineral levels vs. time of osteoblasts on bare (B-Si), microporous and (M-Si) and nanoporous silicon (NSi). Significant differences were observed in the calcium mineral levels produced between day 0 and days, 7, 14 and 21 on microporous silicon versus bare and nanoporous silicon $(a=0.05)$

nanoporous silicon were used as an internal control. It was observed that immunostaining for osteopontin and osteonectin was comparable on all surfaces and osteoblasts continued to produce bone specific proteins on all the substrates even when cultured over a long period.

\subsection{Calcium Quantification Using Alizarin Red Assay}

As shown in Figure $\mathbf{8}$, on day 7 the amount of calcium minerals deposited on bare, micro and nanoporous silicon is almost the same with microporous silicon lagging behind the other substrates. However, on day 14, the amount of calcium minerals increased slightly on nanoporous silicon in comparison to both bare and microporous silicon. After 21 days, calcium mineral level was highest on nanoporous silicon followed by bare and then microporous silicon. Statistically, significant differences were observed for bare, micro and nanoporous silicon at all sampling days $(\alpha=0.1)$. Significant differences were observed in the calcium mineral levels produced between day 0 and day 21 on microporous silicon versus bare and nanoporous silicon $(\alpha=0.05)$.

\section{DISCUSSION}

Implant surface modification plays a vital role in ensuring that implants used to replace damaged or diseased joints are both biocompatible and biointegrative. Increased life expectancy necessitates the need for optimally designed implants that reduce infection, support enhanced bone formation around the implant, and increase implant longevity $[19,20]$. A significant effort has been directed at developing new types of biomimetic scaffolds and surfaces that actively interact with cells to direct and promote tissue development on or around the implant $[21,22]$.

Porous scaffolds with a very complex nanoarchitecture of high surface area and depth would serve as an excellent platform and provide an appropriate environment for the regeneration of bone tissue. Previous studies have established that porous silicon is biodegradable and bioresorbable [16, 17, 23, 24] and capable of supporting hydroxyapatite growth indicating that porous silicon is bioactive and can serve as a bone bonding potential [25]. Moreover, the primary degradation product of pure silicon is monomeric silicic acid $\left(\mathrm{SiOH}_{4}\right)$, which is the most natural form of the element in the environment and is rapidly excreted from the human body by the kidneys [26]. Silicon's true value as a nanomaterial for orthopedic scaffolds or surfaces, however, needs to be fully and properly characterized. Our goal was to fabricate micro- and nanoporous silicon substrates and assess their cell supportive capabilities and osteogenic potential. Electrochemical etching of silicon in HFbased electrolyte produced a nanoporous surface and the addition of ethanol to HF during the fabrication process is proposed to known to increase the wettability of the porous silicon surface and aid in pore infiltration, a factor important for lateral homogeneity and the uniformity in the depth of the PS layer [27]. Ethanol also acts as a surfactant as it removes 
the bubbles (released during the reaction) sticking to the $\mathrm{Si}$ surface. The sterilization of these substrates by placing them in $70 \%$ ethanol also assisted in removing the harsh electrochemical effect of HF, used during the fabrication process, and sterilized the surfaces for osteoblast culture.

Our nanoporous surfaces promoted osteoblast growth and matrix formation that was later mineralized when maintained in culture for an extended period of time. Cells maintained their normal morphology and exhibited the same pattern of initial cell attachment on both bare and nanoporous silicon. Over the 21-day experimental period, however, osteoblasts on nanoporous silicon displayed greater cell adhesion and proliferation than bare. Moreover, the cells began to loose their morphology on bare silicon by the end of twenty-one days. Cytochemical staining was performed on osteoblasts to visualize mineral deposits but visualization was difficult with brightfield microscopy. Accordingly, calcium deposits were quantified using the Alizarin Red assay, which demonstrated that nanoporous silicon also produced the highest level of calcium in comparison to bare and microporous silicon. Studies performed by Xie et al., 2001 [28] on polyethylene terephathalate and Yoshikawa et al., 1998 [29] on nanoporous hydroxyapatite revealed similar results where the initial rate of cell growth was higher for two-dimensional cultures and proliferation stopped after attaining confluency. However, three-dimensional scaffolds supported cell growth for longer time periods in comparison to the two-dimensional scaffolds.

We propose that the nanostructured silicon surfaces stimulated cell adhesion, proliferation and subsequent functionality, as the cells could track the nanoscopic-etched paths, become adherent with subsequent surface occupation, and finally become functional.There are several explanations that might explain this result. The pore dimensions of nanoporous silicon are similar to that of cellular filipodia, thus functioning as anchorage points for the cells leading edge, thus facilitating cell adhesion and migration. Increased cell growth on nanoporous silicon might result from the surface topography as it would provide a stimulus for initial cell adhesion by presenting a surface that adsorbs proteins such as vitronectin and larger proteins that eventually replace these initially adsorbed proteins [30]. Integrin receptors on the osteoblast surface would then mediate cell attachment to these proteins resulting in enhanced cell adhesion [31, 32]. In addition to this, the small pore size of nanoporous silicon would be a better fit for the small MW protein vitronectin (and other small adhesive proteins) with increase protein adsorption resulting in enhanced adhesion.

Structurally, bone as a natural material must provide durability and mechanical stability. Biomaterials used in the repair, substitution, or regeneration of hard tissues must possess strength, corrosion and degradation resistance, and possess significant wear resistance [33, 34]. Metals are able to provide the required mechanical support, however, they have a record of failure to integrate with the tissue at the implantation site, and often fail resulting from bacterial infection or fatigue failure [35, 36]. Ceramics, another potential material, have low tensile strength, are brittle, and are limited to applications in low mechanical load environments [33, 34]. Nanoporous silicon scaffolds could be used to overcome some of the shortcomings of the existing biomaterials used for bone regeneration.

The porosity of the silicon substrates produced using anodic etching can be tuned between 1 and $95 \%$ by varying parameters such as current, resistivity of the wafer or the concentration of the electrolyte [25]. By varying the pore size one might be able to control the binding of proteins that govern cellular attachment, differentiation and mineralization. The advantage of porous silicon compared to other polymers is that a slight change in physical conditions allows for large changes in physical properties, with no effect on its chemistry [26]. Its Young's modulus of elasticity can also be adjusted by varying the porosity level, thus providing mechanical properties consistent with bone tissue. Nanoporous silicon surfaces, including the pores, can be functionalized with antiinfective (antibiotics, antimicrobial peptides, antifungals) and osteogenic inductive agents (biomorphogenetic proteins, pleiotropin) as well as other bioactive molecules (angiogenic, chemotherapeutics, etc.) [12].

Current efforts are directed at designing implant surfaces that reduce (or eliminate) adverse post-surgical tissue responses (infection and failure to integrate) and assist with implant sustainability, by transforming the large surface area offered by the nanoporous surface into multifunctional substrates able to prevent bacterial colonization and incorporate growth factors designed to promote osteoblast adhesion, proliferation and bone tissue formation [36-38]. Functionalization of the nanoporous surface through layer-bylayer assembled nanofilms or hydrogels coatings could be fashioned that incorporate a suite of anti-bacterials providing an immediate to multi-week anti-infective microenvironment permitting the wound site to heal quickly without creating excessive pain or irritation [40,41]. The films and coating could also be designed to prevent a 'burst effect' of bioactive agents but deliver sustained or controlled release and over a defined time period [12, 38, 41]. In contrast to many surface techniques that can be described as a 'one size fits all', the application of multilayer, bioactive polyelectrolyte multilayer or hydrogel nanocoatings could be designed with multiple architectures that is tunable and customizable, features designed to meet specific applications or patient needs.

\section{ACKNOWLEDGEMENTS}

We thank PriyankSukul for his help on microfabrication and nanofabrication of Porous-Si. We also thank Prof. Jillian Buriak, then at Purdue University, for helping with the set-up for anodic oxidation of silicon. Support from Louisiana Governor's Biotechnology (DKM) and to the Louisiana Board of Regents and Pfizer for their funding support (DK). 


\section{AUTHOR CONTRIBUTIONS}

Drs. Kuila and Mills conceived and designed the experiments; Avinash Potluri and Asma Parveen performed the experiments; AsmaParveenand AvinashPotluri conducted and analyzed the data; all authors contributed to the writing of this paper.

\section{CONFLICTS OF INTEREST}

The authors declare no conflict of interest.

\section{REFERENCES}

[1] Medical device coatings market - global industry size, share, Ttrends, Aanalysis \& forecasts http://www.transparencymarketresearch.com/ medical-device-coatings-market.html\#sthash. O0tJiXOF.dpuf

[2] The global joint arthroplasty and orthopedic bone cement market report. Orthop Net News 2012; 23(4); October.

[3] Orthopedic bone cement and casting materials market outlook in BRICS (Brazil, Russia, India, China, South Africa) to 2018.http://www.researchandmarkets.com/reports/2228361/.

[4] Zhao Y, Xiong T, Huang W. Applied Surface Science Effect of heat treatment on bioactivity of anodic titania films. Appl Surf Sci 2010; 256: 3073-3076 https://doi.org/10.1016/i.apsusc.2009.11.075

[5] Hetrick EM, Schoenfish MH. Reducing implant-related infections: active release strategies. Chem Soc Rev 2006; 35: 780-789. https://doi.org/10.1039/b515219b

[6] Hardes J, Ahrens H, Gebert C, Streitbuerger A, Buerger H, Erren M, et al. Lack of toxicological side-effects in silver-coated megaprostheses in humans. Biomaterials 2006; 28: 2869-75. https://doi.org/10.1016/i.biomaterials.2007.02.033

[7] Zhao LZ, Wang HR, Huo KF, Cui LY, Zhang WR, Ni, HW et al. Antibacterial nano-structured titania coating incorporated with silver nanoparticles. Biomaterials 2012; 32: 5706-16. https://doi.org/10.1016/j.biomaterials.2011.04.040

[8] Hickok NJ, Shapiro IM. Immobilized antibiotics to prevent orthopaedic implant infections. Adv Drug Deliv Rev 2012; 64: 1165-76. https://doi.org/10.1016/j.addr.2012.03.015

[9] Wang Q, Yan J, Yang J, Li B. Nanomaterials promise better bone repair. Mat Today 2016; 19(8): 451-63. https://doi.org/10.1016/i.mattod.2015.12.003

[10] Darouiche RO. Treatment of infections associated with surgical implants. New Eng J Med 2004; 350: 1422-9. https://doi.org/10.1056/NEJMra035415

[11] Goodman SB, Zhenyu Y, Keeney M, Yang F. The future of biologic coatings for orthopaedic implants. Biomaterials 2013; 34: 3174-83. https://doi.org/10.1016/i.biomaterials.2013.01.074

[12] Weerachai S. Biological responses to new advanced surface modifications of endosseous medical implants. Bone Tiss Regen Insights 2009; 2: 1-11.

[13] Issacson B, Jeyalina S. Osseointegration: a review of the fundamentals of assuring cementless skeletal fixation Orthoped. Res Rev 2014; 6: 55-65. https://doi.org/10.2147/orr.s59274

[14] Nikhah M, Edalat F, Manoucheri S, Khademhosseini A. Engineering microscale topographies to control the cell-substrate interface. Biomaterials 2012: 33 : 5230-5246. https://doi.org/10.1016/i.biomaterials.2012.03.079

[15] Crawford GA, Chawla N, Das K, Bose S, Bandyopadhyay A. Microstructure and deformation behavior of biocompatible $\mathrm{TiO}_{2}$ nanotubes on titanium substrate. Acta Biomat 2007; 3: 359-67. https://doi.org/10.1016/i.actbio.2006.08.004

[16] Sun W, Puzas JE, Shei TJ, Liu, X, Fauchet PM. Nano- to microscale porous silicon as a cell interface for bone-tissue engineering. Adv Mater 2007; 19: 921-924. https://doi.org/10.1002/adma.200600319

[17] Coffer JL, Whitehead, MA, Nagesha DK, Mukherjee P, Akkaraju G, et al. Porous silicon-based scaffolds for tissue engineering and other biomedical applications. Phys Stat Sol (A) 2005; 202: 1451-1455. https://doi.org/10.1002/pssa.200461134
$[18]$

Sukul P. MS Thesis, "Fabrication and Characterization of surface modified porous silicon and indium tin oxide for device applications." Louisiana Tech University, Ruston, LA 2006.

[19] Chiara G, Letzia F, Lorenzo F, Edoardo S, Diego S, et al Nanostructured biomaterials for tissue engineered bone tissue reconstruction. Int J Mol Sci 2012; 13: 737-757. https://doi.org/10.3390/iims13010737

[20] Goodman SB, Zhenyu Y, Keeney M, Yang F. The future of biologic coatings for orthopaedic implants. Biomaterials 2013; 34: 3174-83. https://doi.org/10.1016/j.biomaterials.2013.01.074

[21] Alvarez K, Nakajima H. Metallic scaffolds for bone regeneration. Materials 2009; 2: 790-832.

https://doi.org/10.3390/ma2030790

[22] Issacso B, Jeyalina S. Osseointegration: a review of the fundamentals of assuring cementless skeletal fixation. Orthop Res Rev 2014; 6: 5565 https://doi.org/10.2147/ORR.S59274

[23] Canham LT. Bioactive silicon structure fabrication through nanoetchingtechniques. Adv Mat 1995; 7: 1033-1037. https://doi.org/10.1002/adma.19950071215

[24] Canham LT, Reeves CL, King DO, Branfield PJ, Crabb JG, Ward CL. Bioactive polycrystalline silicon. Adv Mat 1996; 8: 850-853. https://doi.org/10.1002/adma.19960081020

[25] Canham LT. Porous Silicon as a Therapeutic Biomaterial, IEEE October 2000; 12-14: 109-112.

[26] Stewart MP, Buriak JM. Chemical and biological applications of silicon technology. Adv Mater 2000; 12: 859-869. https://doi.org/10.1002/1521-4095(200006)12:12<859::AIDADMA859>3.0.CO;2-0

[27] Bisia O, Ossicinib S, Pavesic L. Porous silicon: a quantum sponge structure for silicon based optoelectronics. Surface Science Reports 2000; 38: 1-126. https://doi.org/10.1016/S0167-5729(99)00012-6

[28] Xie Y, Yang ST, Kniss DA. Three-dimensional cell-scaffold constructs promotes efficient gene transfection: Implications for cell-based gene therapy. Tissue Eng 2007; 7: 585-595. https://doi.org/10.1089/107632701753213200

[29] Yoshikawa T, Ohgushi H, Akahana M, Tamai S, Ichijima K. Analysis of gene expression on osteogenic cultured marrow-hydroxyapatite constructs implanted at ectopic sites: A comparison with the osteogenic ability of cancellous bone. J of Biomed Mat Res 1998; 41 568-573.

https://doi.org/10.1002/(SICI)1097-4636(19980915)41:4<568::AIDJBM8>3.0.CO;2-A

[30] Park J, Bauer S, von der Mark K, Schmuki P. Nanosize and vitality: $\mathrm{TiO}_{2}$ nanotube diameter directs cell fate. Nano Letters 2007; 7: 168691.

https://doi.org/10.1021/nl070678d

[31] Meyer U, Butcher A, Wiesmann HP, Joos U, Jones DB. Basic reactions of osteoblasts on structured material surfaces. Eur Cells and Mat 2005; 9: 39-49.

https://doi.org/10.22203/eCM.v009a06

[32] Garcia AJ, Reyes CD. Bio-adhesive surfaces to promote osteoblasts differentiation and bone formation. J of Dental Res 2005; 84: 407-413. https://doi.org/10.1177/154405910508400502

[33] Salgado AJ, Coutinho OP, Reis RL. Bone tissue engineering: State of the art and future trends. Macromolecular Biosci 2004; 4: 743-765 https://doi.org/10.1002/mabi.200400026

[34] Yaszemski MJ, Oldham JB, Lu L, Currier BL. Bone Engineering, 1st Ed, Em squared, Toronto, Canada 2000.

[35] Navarro M, Michardi A, Castano O, Planell JA. Biomaterials in orthopaedics Interface 2008; 5: 1137-1158.

[36] Stevens MM. Biomaterials for bone tissue engineering Materials Today 2008; 11: 18-25. https://doi.org/10.1016/S1369-7021(08)70086-5

[37] Leguen E, Chassepot A, Decher G, Schaaf P, Voegel J, Jessel N. Bioactive coatings based on polyelectrolyte multilayer architectures functionalized by embedded proteins, peptides or drugs. Biomol Eng 2007; 24: 33-41.

https://doi.org/10.1016/i.bioeng.2006.05.023

[38] Chuang HF, Smith RC, Hammond PT. Polyelectrolyte multilayers for tunable release of antibiotics. Biomacromolecules 2008; 9: 16601668.

https://doi.org/10.1021/bm800185h

[39] Zhang L, Li B, Zhi ZL, Haynie DT. Perturbation of nanoscale structure of polypeptide multilayer thin films. Langmuir 2005; 21 : 5439-5445. https://doi.org/10.1021/la0501381 
[40] Guillot R, Gilde F, Becquart P, Sailhan F, et al. The stability of BMP loaded polyelectrolyte multilayer coatings on titanium. Biomaterials 2013; 34: 5737-5746.

https://doi.org/10.1016/j.biomaterials.2013.03.067
[41] Leguen E, Chassepot A, Decher G, Schaaf P, Voegel J-C, Jessel N Bioactive coatings based on polyelectrolyte multilayer architectures functionalized by embedded proteins, peptides or drugs. Biomol Eng 2007: 24: 33-41.

https://doi.org/10.1016/j.bioeng.2006.05.023

(C) 2017 Parveen et al.; Licensee Lifescience Global.

This is an open access article licensed under the terms of the Creative Commons Attribution Non-Commercial License (http://creativecommons.org/licenses/by-nc/3.0/) which permits unrestricted, non-commercial use, distribution and reproduction in any medium, provided the work is properly cited. 